Proceedings

\title{
Ozone Sensors Working at Room Temperature Using Zinc Oxide Nanocrystals Annealed at Low Temperature ${ }^{+}$
}

\author{
Sandrine Bernardini 1,*, Mohamed Hameda Benchekroun 1, Tomas Fiorido 1, Khalifa Aguir 1, \\ Marc Bendahan 1, Sadok Ben Dkhil 2, Meriem Gaceur ${ }^{2}$, Jörg Ackermann ${ }^{2}$, Olivier Margeat ${ }^{2}$ and \\ Christine Videlot-Ackermann ${ }^{2}$ \\ 1 Aix Marseille Univ, Université de Toulon, CNRS, IM2NP, Marseille 13397, France; \\ hameda.benchekroun1993@gmail.com (M.H.B.); tomas.fiorido@im2np.fr (T.F.); khalifa.aguir@im2np.fr \\ (K.A.); marc.bendahan@im2np.fr (M.B.) \\ 2 Aix Marseille Univ, CNRS, CINAM, Marseille 13288, France; sadok.bendkhil@gmail.com (S.B.D.); \\ mgaceur@gmail.com (M.G.); ackermann@cinam.univ-mrs.fr (J.A.); olivier.margeat@univ-amu.fr (O.M.); \\ videlot@cinam.univ-mrs.fr (C.V.-A.) \\ * Correspondence: sandrine.bernardini@im2np.fr; Tel.: +33-049-128-8971 \\ + Presented at the Eurosensors 2017 Conference, Paris, France, 3-6 September 2017.
}

Published: 11 August 2017

\begin{abstract}
We focus on ozone $\left(\mathrm{O}_{3}\right)$ detection at ambient temperature by Zinc Oxide $(\mathrm{ZnO})$ nanoparticles (NPs) deposited on $\mathrm{Si} / \mathrm{SiO}_{2}$ by spin coating from colloidal solutions as sensitive layers for air quality monitoring. We establish that at room temperature using continuous Ultra-Violet (UV) light irradiation enhances the sensing responses. Three annealing temperatures of $\mathrm{ZnO}$ films were performed to compare the sensing properties. These sensors present repeatable responses towards $\mathrm{O}_{3}$ with fast responses for concentrations as low as $35 \mathrm{ppb}$ with processes compatible with most of flexible substrates.
\end{abstract}

Keywords: ozone gas; room-temperature; UV-photoactivated; $\mathrm{ZnO}$ nanoparticles; environment

\section{Introduction}

Chemical gas sensors are applied in many areas, such as agriculture, medical diagnosis and detection of environmental pollutants [1-3]. The naturally present ozone $\left(\mathrm{O}_{3}\right)$ in the atmosphere is harmful even at low concentrations $(<200 \mathrm{ppb})$. It leads to health problems such as inflammation or respiratory tract [4]. It well known that Metal Oxide Semiconductor (MOX) sensors require high operating temperature $\left(>200{ }^{\circ} \mathrm{C}\right)$ to accelerate molecule chemical reactivity in the adsorption and desorption process. We aimed to fabricate MOX sensors on flexible substrate to fit shapes on smart object for $\mathrm{O}_{3}$ monitoring. However, most of flexible substrates do not resist to temperature higher than $120^{\circ} \mathrm{C}$. As far as we know, no study reports $\mathrm{O}_{3}$ MOX sensors using Zinc Oxide (ZnO) nanoparticles (NPs) with annealing temperature lower than $150{ }^{\circ} \mathrm{C}$. Furthermore, to detect low $\mathrm{O}_{3}$ concentrations at room-operating temperature, we replaced heating excitation by continuous Ultra-Violet (UV) Light-Emitting Diode (LED) for UV illumination $(\lambda=390 \mathrm{~nm}$ ). Indeed, photogenerated carriers improve the layer conductivity [5].

\section{Materials and Methods}

Our gas sensor consists of Ti/Pt interdigitated electrodes ( 5 and $100 \mathrm{~nm}$, respectively) deposited on $\mathrm{Si} / \mathrm{SiO}_{2}$ by magnetron sputtering. To optimize the sensitive layer performances, three solutions based on ZnO NPs with or without ethanolamine (EA) were deposited during $30 \mathrm{~s}$ at either 1500 or 
$2000 \mathrm{rpm} / \mathrm{min}$. Thus, we prepared five different sensitive layers with resulting layer thicknesses measured by a Veeco Dektak 6M stylus profiler (Veeco, USA) (see Table 1).

Table 1. Five sensitive layers with resulting thickness based on ZnO NPs in solutions at 10 or 30 $\mathrm{mg} / \mathrm{mL}$ in isopropanol, with or without EA.

\begin{tabular}{ccccc}
\hline S1 & S2 & S3 & S4 & S5 \\
\hline $30 \mathrm{mg} / \mathrm{mL}$ & $30 \mathrm{mg} / \mathrm{mL}$ & $10 \mathrm{mg} / \mathrm{mL}$ & $10 \mathrm{mg} / \mathrm{mL}$ & $30 \mathrm{mg} / \mathrm{mL}$ \\
without EA & with EA & with EA & with EA & with EA \\
$0 \%$ & $0.2 \%$ & $0.2 \%$ & $0.2 \%$ & $0.2 \%$ \\
$2000 \mathrm{rpm} / \mathrm{min}$ & $2000 \mathrm{rpm} / \mathrm{min}$ & $2000 \mathrm{rpm} / \mathrm{min}$ & $1500 \mathrm{rpm} / \mathrm{min}$ & $1500 \mathrm{rpm} / \mathrm{min}$ \\
$100 \pm 10 \mathrm{~nm}$ & $90 \pm 10 \mathrm{~nm}$ & $80 \pm 10 \mathrm{~nm}$ & $180 \pm 15 \mathrm{~nm}$ & $205 \pm 15 \mathrm{~nm}$ \\
\hline
\end{tabular}

Previous studies have shown that $0.2 \%$ volume of EA, a short-chain surfactant, gives aggregate-free solution [6,7]. ZnO NPs were deposited by spin coating on rigid substrates to compare the sensing performances for three post-annealing temperatures: $80{ }^{\circ} \mathrm{C}, 150{ }^{\circ} \mathrm{C}$ and $300{ }^{\circ} \mathrm{C}$ during $30 \mathrm{~min}$, respectively. With a boiling point of $82.6^{\circ} \mathrm{C}$ for isopropanol, solvent molecules were completely evaporated for drying temperature reaching $150^{\circ} \mathrm{C}$. The EA surfactant molecules stayed adsorbed on the surface of NPs at least up to the boiling point at $170{ }^{\circ} \mathrm{C}$. A $0.1 \mathrm{~V}$ dc voltage was applied to the sample while the electrical resistance was monitored using a Keithley Model 2450 SourceMeter source measure unit (SMU) Instrument (Keithley, USA). Dry air was used as both the reference and the carrier gas, maintaining a constant total flow of 500 standard cubic centimeters per minute (SCCM) via mass flow controllers. Oxidizing oxygen using a UV pen-ray lamp, resulting in a generation of $\mathrm{O}_{3}$ output level from 35 to $165 \mathrm{ppb}$.

\section{Results and Discussion}

By High-Resolution Transmission Electron Microscope (HR-TEM) JEOL 3010, ZnO NPs, ZnO NPs drop casted from a diluted solution on a mesh-coated carbon film (Figure 1a), presented a homogeneous size (diameter about $5 \mathrm{~nm}$ ) and shape dispersions [6,7]. By scanning electron microscope (SEM) a JEOL JSM 6320F, analysis of spin-coated $\mathrm{ZnO}$ thin films highlights the formation of uniform and densely packed agglomerates (Figure 1b).

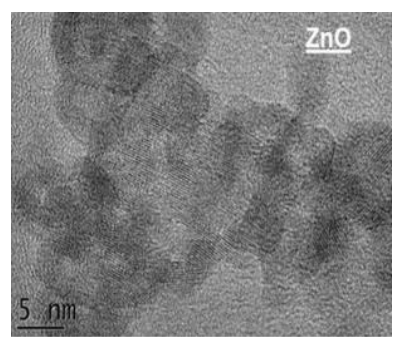

(a)

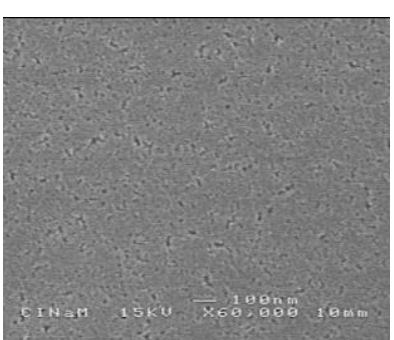

(b)

Figure 1. (a) TEM image of $\mathrm{ZnO}$ nanospheres at $30 \mathrm{mg} / \mathrm{mL}$ with $0.2 \%$ ethanolamine and (b) SEM image of a spin-coated $\mathrm{ZnO}$ thin film as $\mathrm{S} 2$ and post-annealed at $80^{\circ} \mathrm{C}$.

Figure 2 presents $\mathrm{O}_{3}$ detection with sensitive layer without and with $\mathrm{EA}$ for $30 \mathrm{mg} / \mathrm{mL}$ of $\mathrm{ZnO}$ nanocrystals annealed at $80{ }^{\circ} \mathrm{C}$. For comparable thickness $(\sim 100 \mathrm{~nm})$ and same concentration $(30 \mathrm{mg} / \mathrm{mL}$ ) of $\mathrm{ZnO}$, the sensor responses with EA are slightly lower than the one without EA due to grafting and isolating EA properties [7]. 


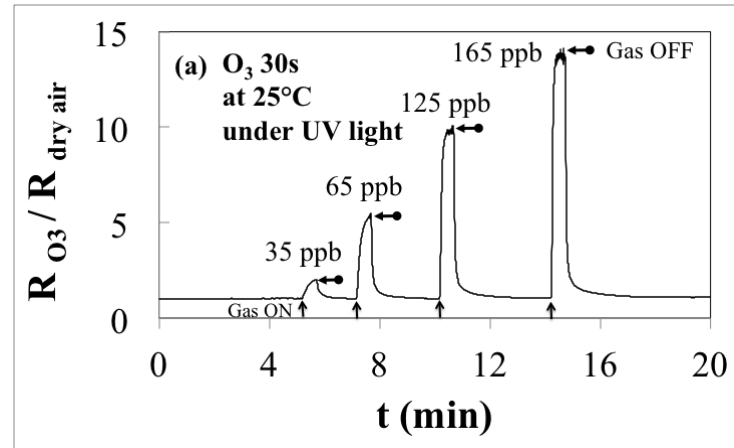

(a)

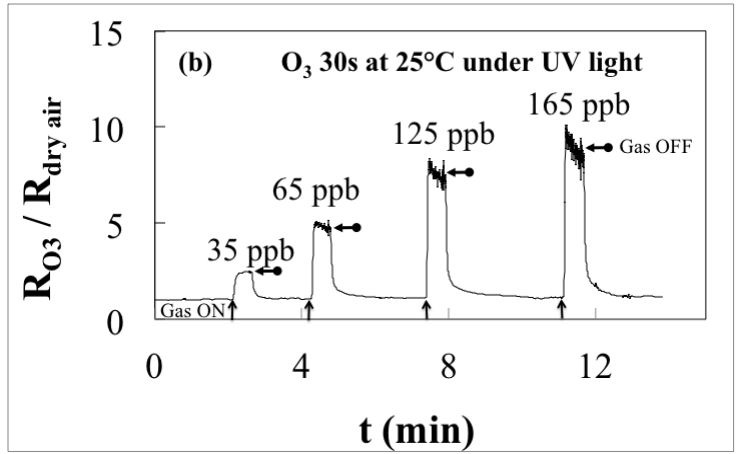

(b)

Figure 2. Normalized responses at $25^{\circ} \mathrm{C}$ for $\mathrm{O}_{3}$ sensors based on $\mathrm{ZnO}$ at $30 \mathrm{mg} / \mathrm{mL}$ (post-annealed at $80^{\circ} \mathrm{C}$ ) under UV light (a) without EA (S1) and (b) with EA (S2).

Figure 3 exhibits higher amplitude response for S5 and good repeatability for low $\mathrm{O}_{3}$ concentrations without sensor saturation.

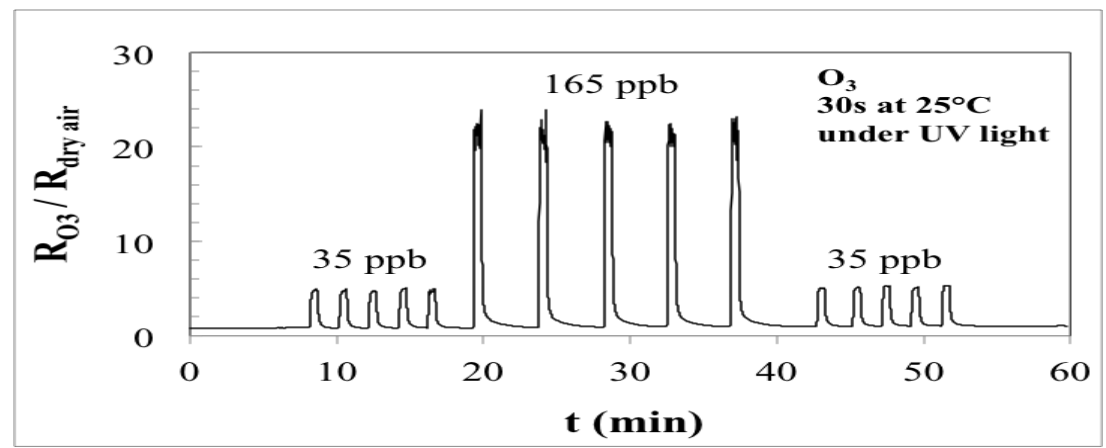

Figure 3. Repeatability of a $200 \mathrm{~nm}$ thick sensor with a sensitive layer based on $\mathrm{ZnO}$ at $30 \mathrm{mg} / \mathrm{mL}$ with EA (S5) and post-annealed at $80^{\circ} \mathrm{C}$, working at $25^{\circ} \mathrm{C}$ under continuous UV illumination for 35 $\mathrm{ppb}$ and $165 \mathrm{ppb}$ of $\mathrm{O}_{3}$.

Figure 4 demonstrates that sensitive layers gave already good $\mathrm{O}_{3}$ detection at $25^{\circ} \mathrm{C}$ even with a low post-annealing temperature $\left(80^{\circ} \mathrm{C}\right)$ which is compatible with most of flexible substrates.

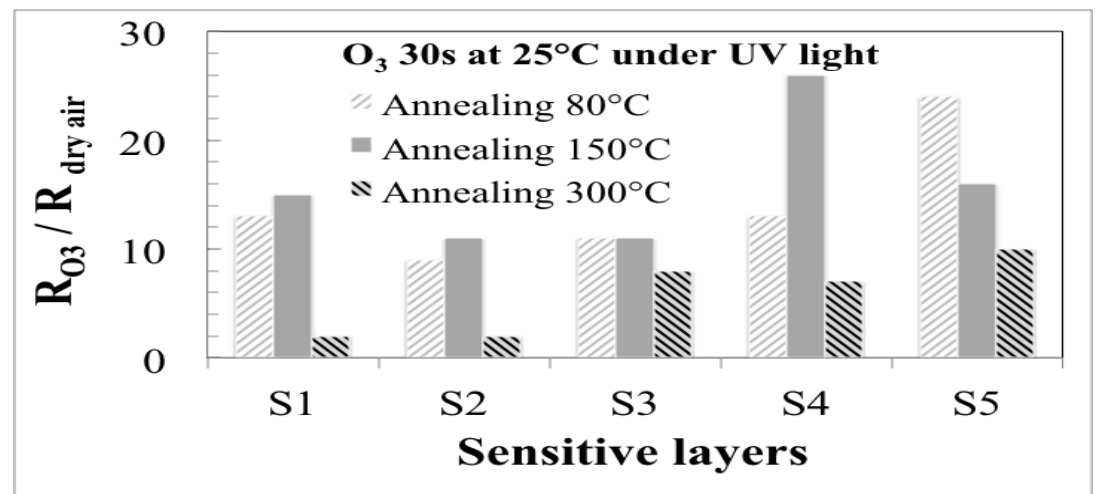

Figure 4. Sensor responses for $165 \mathrm{ppm}$ of $\mathrm{O}_{3}$ at $25{ }^{\circ} \mathrm{C}$ under UV light for three post-annealing temperatures.

To compare the $\mathrm{O}_{3}$ detection at room temperature and high classical temperature detection $\left(275^{\circ} \mathrm{C}\right)$, measurements have been realized on $\mathrm{S} 4$ post-annealed at $300^{\circ} \mathrm{C}$. No detection was possible in dark at room temperature due to the high layer resistivity. Figure 5 revealed that the amplitude is higher at $275^{\circ} \mathrm{C}$ in dark and under UV light than at room temperature. However, these temperatures cannot be used on all flexible substrates. 


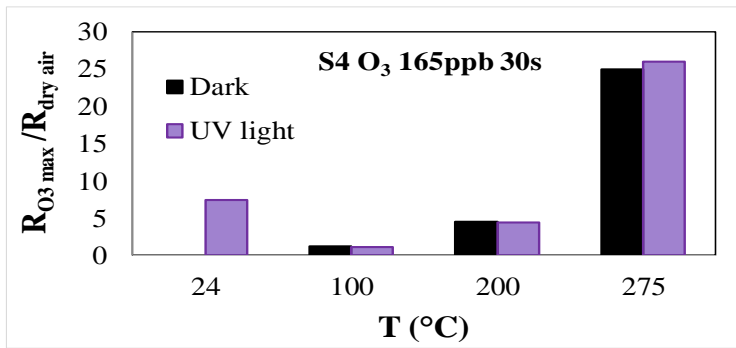

Figure 5. $\mathrm{O}_{3}$ sensor responses of $\mathrm{S} 4$ (post-annealed at $300{ }^{\circ} \mathrm{C}$ ) for working temperatures from 25 to $275{ }^{\circ} \mathrm{C}$ without and with UV light.

Based on our studies on Kapton substrate showing $\mathrm{NO}_{2}$ detection in dark at lower temperature than for $\mathrm{O}_{3}$ detection by $\mathrm{ZnO}$ NPs [8], we are now focusing our attention on $\mathrm{NO}_{2}$ detection by these samples in the same conditions with UV light and/or temperature excitations.

\section{Conclusions}

This work reported an ambient temperature way to detect ozone molecules by sensors based on thin-film ZnO NPs structures synthetized by hydrothermal process. Gas sensing measurements showed the great potential of $\mathrm{ZnO} N P$ s, which display a fast response, short recovery time, at room temperature under UV-light irradiation. This versatile methodology provides an alternative way to manufacture gas sensor devices, operating at room temperatures, which is compatible with most of flexible substrates. Electrical resistance measurements at room temperature under UV irradiation showed that $\mathrm{ZnO}$ thin films were sensitive even at low $\mathrm{O}_{3}$ concentration ( $35 \mathrm{ppb}$ ).

Acknowledgments: The authors would like to thank A. Combes for his technical support in this work.

Conflicts of Interest: The authors declare no conflict of interests.

\section{References}

1. Baruah, S.; Dutta, J. Nanotechnology applications in pollution sensing and degradation in agriculture: A review. Environ. Chem. Lett. 2009, 7, 191-204, doi:10.1007/s10311-009-0228-8.

2. Wilson, A.D. Diverse Applications of Electronic-Nose Technologies in Agriculture and Forestry. Sensors 2013, 13, 2295-2348, doi:10.3390/s130202295.

3. Kim, I.D.; Rothschild, A.; Tuller, H.L. Advances and new directions in gas-sensing devices. Acta Mater. 2013, 61, 974-1000, doi:10.1016/j.actamat.2012.10.041.

4. Catto, A.C.; Silva, L.F.D.; Bernardi, M.I.B.; Bernardini, S.; Aguir, K.; Longo, E.; Mastelaro, V.R. Local structure and surface properties of $\mathrm{Co}_{\times} \mathrm{Zn}_{1-\mathrm{x}} \mathrm{O}$ thin films for ozone gas sensing. ACS Appl. Mater. Interfaces 2016, 8, 26066-26072, doi:10.1021/acsami.6b08589.

5. Da Silva, L.F.; M'Peko, J.C.; Catto, A.C.; Bernardini, S.; Mastelaro, V.R.; Aguir, K.; Ribeiro, C.; Longo, E.

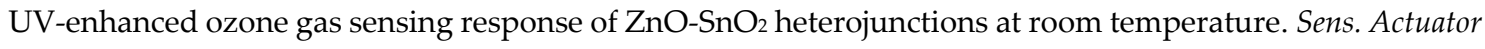
B 2017, 240, 573-579, doi:10.1016/j.snb.2016.08.158.

6. Dkhil, S.B.; Duché, D.; Gaceur, M.; Thakur, A.K.; Aboura, F.B.; Escoubas, L.; Simon, J.J.; Guerrero, A.; Bisquert, J.; Garcia-Belmonte, G. Interplay of Optical, Morphological, and Electronic, Effects of ZnO Optical Spacers in Highly Efficient Polymer Solar Cells. Adv. Energy Mater. 2014, 4, 1400805-1400817. 
7. Diallo, A.K.; Gaceur, M.; Dkhil, S.B.; Didane, Y.; Margeat, O.; Ackermann, J.; Videlot-Ackermann, C. Impact of surfactants covering nanoparticles on solution-processed field-effect transistors: From dispersion state to solid state. Colloids Surf. A 2016, 500, 214-221, doi:10.1016/j.colsurfa.2016.04.036.

8. Acuautla, M.; Bernardini, S.; Gallais, L.; Fiorido, T.; Patout, L.; Bendahan, M. Ozone flexible sensors fabricated by photolithography and laser ablation process based on $\mathrm{ZnO}$ nanoparticles. Sens. Actuator B 2014, 203, 602-611, doi:10.1016/j.snb.2014.07.010.

(C) 2017 by the authors. Licensee MDPI, Basel, Switzerland. This article is an open access article distributed under the terms and conditions of the Creative Commons Attribution (CC BY) license (http://creativecommons.org/licenses/by/4.0/). 